\title{
Biosynthesis of resveratrol using metabolically engineered Escherichia coli
}

\author{
Jin Yeong Park ${ }^{1 \dagger}$, Jeong-Hyeon Lim ${ }^{2 \dagger}$, Joong-Hoon Ahn ${ }^{1}$ and Bong-Gyu Kim²*
}

\begin{abstract}
Resveratrol (3,5,4'-trihydroxy-trans-stilbene) is a phenolic compound widely used in pharmaceutics and nutraceutics. Although resveratrol is produced by some plant species, including grapes, peanuts, and berries, the content of resveratrol and its derivatives are very low. Therefore, an alternative biosynthetic method using microorganisms, such as Escherichia coli, has been developed over the past two decades. In the present study, a resveratrol-over-producing E. coli strain was developed using three strategies. First, we increased the synthesis of $p$-coumaric acid, a precursor of resveratrol, by manipulating genes in the shikimate pathway of $E$. coli. Second, three genes involved in resveratrol biosynthesis, such as tyrosine ammonia lyase (TAL), 4-coumaroyl CoA ligase (4CL), and stilbene synthase (STS), were cloned from diverse sources, such as plants and microorganisms, and the best combination was selected to maximize resveratrol production in E. coli. Finally, culture conditions, such as cell concentration, culture temperature, and carbon sources, were established for optimal resveratrol production. Through these strategies, approximately $80.4 \mathrm{mg} / \mathrm{L}$ of resveratrol was biosynthesized after $48 \mathrm{~h}$ of culture using glycerol as a carbon source.
\end{abstract}

Keywords: Escherichia coli, Metabolic engineering, Phenolic compounds, Resveratrol

\section{Introduction}

Polyphenols are plant secondary metabolites and valuable sources for the development of cosmetic materials, functional food ingredients, and pharmaceuticals [1-3]. Polyphenols are generally derived through the phenylpropanoid pathway [4]. Depending on their carbon skeleton, they can be classified into four classes, such as phenolic acids including gallic acid and salicylic acid composed of $\mathrm{C}_{6}-\mathrm{C}_{1}$ skeleton, hydroxycinnamic acid including cinnamic acid, $p$-coumaric acid, and caffeic acid composed of $\mathrm{C}_{6}-\mathrm{C}_{3}$ skeleton, stilbene including resveratrol, piceatannol, and pallidol composed of $\mathrm{C}_{6}-\mathrm{C}_{2}-\mathrm{C}_{6}$ skeleton, flavonoids including naringenin, quercetin, and genistein composed of $\mathrm{C}_{6}-\mathrm{C}_{3}-\mathrm{C}_{6}$ skeleton [4-6].

\footnotetext{
*Correspondence: dkimbk@gntech.ac.kr

${ }^{\dagger}$ Jin Yeong Park and Jeong-Hyeon Lim contributed equally to this work

2 Department of Forest Resources, Gyeongnam National

University of Science and Technology, 33 Dongjin-ro, Jinju 52725,

Gyeongsangman-do, Korea

Full list of author information is available at the end of the article
}

Resveratrol (3,5,4'-trihydroxy-trans-stilbene) is a polyphenolic compound containing a $\mathrm{C}_{6}-\mathrm{C}_{2}-\mathrm{C}_{6}$ skeleton. It is synthesized naturally in several plants in response to pathogenic fungi and bacteria or wounds caused by insects and herbivores [7-9]. Resveratrol was first isolated from the white hellebore roots and subsequently isolated from Polygonum cuspidatum [10, 11]. Most of the commercial resveratrol throughout the world is extracted from P. cuspidatum E. et Z. In recent years, the biological effects of resveratrol on atherosclerosis and coronary heart disease, and its anticancer, antileukemic, and immune-modulating activities have been well documented through a variety of physiological and pharmacological studies [12, 13]. In plants, resveratrol is synthesized from the aromatic amino acid phenylalanine through the sequential reaction of four enzymes, phenylalanine ammonia lyase (PAL), cinnamic acid 4-hydroxylase $(\mathrm{C} 4 \mathrm{H})$, 4-coumaroyl-CoA synthase (4CL), and stilbene synthase (STS) (Fig. 1) [14]. PAL is responsible for the deamination of L-phenylalanine to produce trans-cinnamic acid. Subsequently, trans-cinnamic acid is converted into $p$-coumaric acid (4-hydroxy cinnamic 


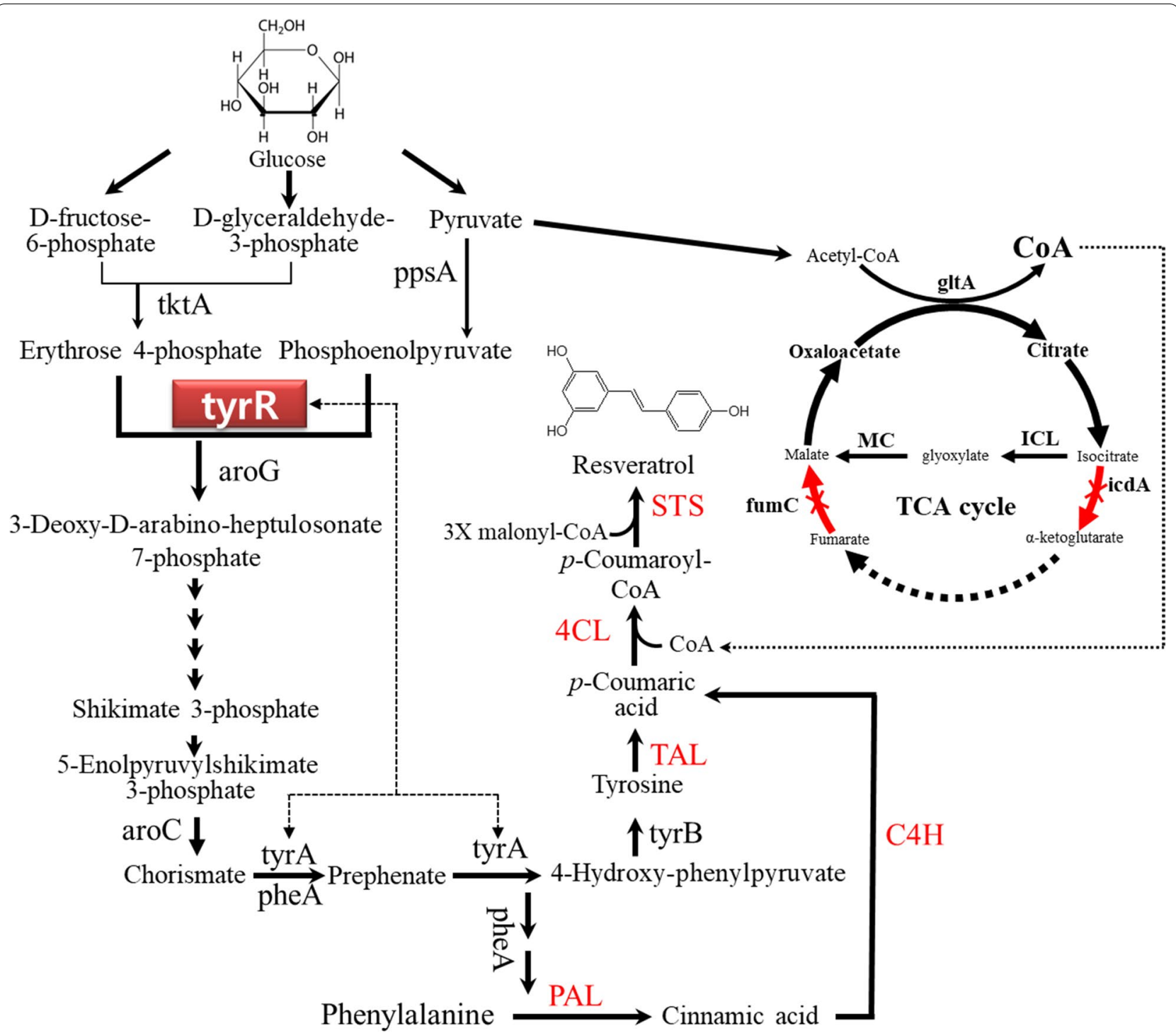

Fig. 1 Biosynthetic pathway of resveratrol production from glucose. ppsA, phosphoenolpyruvate synthetase; $t$ tkt , transketolase; tyrR, phenylalanine DNA-binding transcription repressor; aroG, deoxyphosphoheptonate aldolase; aroC, chorismate synthase; tyrA, prephenate dehydrogenase; pheA, prephenate dehydratase; tyrB, phenylalanine aminotransferase; TAL, tyrosine ammonia-lyase; 4CL, 4-coumaroyl-CoA ligase; STS, stilbene synthase; PAL, phenylalanine ammonia-lyase; C4H, cinnamic acid 4-hydroxylase; icdA, isocitrate dehydrogenase; glaA, Citrate synthase; fumC, fumarase; ICL, isocitrate lyase; $M S$, malate synthase

acid) by $\mathrm{C} 4 \mathrm{H}$ (Fig. 1). $p$-Coumaric acid is converted into $p$-coumaroyl-CoA by $4 \mathrm{CL}$ with coenzyme $\mathrm{A}$ as a cosubstrate. $p$-Coumaroyl-CoA is condensed with three malonyl-CoA units through the sequential reaction of STS, belonging to polyketide III (PKS III), to produce resveratrol [15]. Because the functional expression of $\mathrm{C} 4 \mathrm{H}$ (Fig. 1), a member of the P450 genes, is generally difficult in $E$. coli, tyrosine ammonia lyase (TAL), which catalyzes the deamination of tyrosine to $p$-coumaric acid, has been recently employed for the biosynthesis of various polyphenols [16]. To synthesize resveratrol from tyrosine in E. coli, three genes, $T A L, 4 C L$, and STS, are required (Fig. 1). However, tyrosine is a limiting factor for the synthesis of resveratrol from glucose. To increase the tyrosine content in E. coli, metabolic engineering approaches have been applied in E. coli. [17, 18].

Over many decades, natural compounds derived from plants have been the materials of great medicinal value associated with human health benefits $[19,20]$. However, there are some obstacles that must be overcome, including seasonal and spatial limitations, low yields, and complicated refining processes, such as extraction 
and isolation, before the commercial usage of these biologically active molecules [21]. For these reasons, some alternative production methods have been developed, including plant cell or hairy root culture and simple biotransformation or de novo synthesis using microorganisms, such as E. coli and yeast, for the production of pharmaceutically useful substances of plant origin [18, 22-24]. Among them, E. coli is an excellent host for producing large-scale commercial commodities because their metabolic pathway is well known and various techniques of gene manipulation are well established [26]. In addition, the synthesized phenolic compounds can be easily purified using simple organic solvents such as ethyl acetate $[18,25]$. Using $E$. coli, a number of medicinally important compounds, such as hydroxycinnamic acids, coumarins, stilbenoids, flavonoids, terpenoids, and alkaloids, have been successfully synthesized [18, 27-29, 35].

Most of the previous studies related to the production of resveratrol in $E$. coli started from $p$-coumaric acid. The titer was approximately $16 \mathrm{mg} / \mathrm{L}$ resveratrol from $800 \mathrm{mg}$ of $p$-coumaric acid, when E. coli BL21 (DE3) containing the gene $4 C L$ from Nicotiana tabacum and the gene STS from Vitis vinifera was used [30], whereas when the $E$. coli JM109 strain transformed with the gene 4CL from Arabidopsis thaliana and STS from Arachis hypogaea was used, the amount of resveratrol was over $100 \mathrm{mg} / \mathrm{L}$ [31]. Lim et al. [32] developed a metabolically engineered E. coli strain capable of producing high-yield resveratrol $(2.3 \mathrm{~g} / \mathrm{L})$ by feeding on $15 \mathrm{mM} p$-coumaric acid. However, because $p$-coumaric acid is relatively expensive compared to glucose, the synthesis of resveratrol from glucose, a renewable source, is an attractive alternative approach. Recently, resveratrol was successfully synthesized from glucose by introducing three genes, $T A L$, $4 C L$, and STS, into E. coli [28]. Yuan et al. [33] reported resveratrol production from glucose using modular engineering of an E. coli-Saccharomyces cerevisiae co-culture, and the yield of resveratrol was $28.5 \mathrm{mg} / \mathrm{L}$. Wang et al. [28] reported the production of $114.4 \mathrm{mg} / \mathrm{L}$ of resveratrol from glucose, but $3 \mathrm{mM}$ tyrosine was added to the to the culture medium for resveratrol biosynthesis. Although previous studies have demonstrated the de novo production of resveratrol from glucose, the potential to improve productivity remains.

In this work, we describe microbial resveratrol production from glucose using E. coli. We engineered the tyrosine biosynthesis pathway for the stable supply of tyrosine by metabolic engineering, introduced three resveratrol biosynthetic genes, and selected the optimal combination of resveratrol biosynthetic genes. In addition, in previous studies, a mutant was used to supply more precursor (tyrosine) for resveratrol biosynthesis [16, 28], but in this study, we used not only E. coli mutant for tyrosine but also overexpressed genes for tyrosine biosynthesis in order to synthesize resveratrol from glucose (without supplying tyrosine). Then, we optimized the fermentation conditions such as carbon source, initial cell density, and culture temperature. Finally, the combined effect of genetic modification and culture conditions increased the final resveratrol titer to $80 \mathrm{mg} / \mathrm{L}$. The strategy described here will be applicable as an alternative production tool of resveratrol, which can be used in various applications in food, pharmaceutical, and nutraceutical industry.

\section{Materials and methods \\ Plasmid constructs}

The TAL gene from Saccharothrix espanaensis (SeTAL) was previously cloned between EcoRI and NotI sites of pCACYCDuet vector [18]. Three genes of $4 L C$ from Streptomyces coelicolar A(3) (Sc4CL), Oryza sativa (Os4CL), and Lithospermum erythrorhizon (Le4CL) were cloned between BamHI and Not I of pCDFDuet, and named PC-Sc4CL, PC-Os4CL, and PC-Le4CL. The gene $4 C L$ from Petroselinum crispum (Pc4CL) was cloned between the EcoRI and NotI sites of pCDFDuet and named PC-Pc4CL. STS from Vitis vinifera (VvSTS) was introduced into multiple cloning site 2 using EcoRV and XhoI sites of PC-Sc4CL, PC-Os4CL, PC-Pc4CL, and PCLe4CL. The resulting plasmids, in which each gene was controlled by the $\mathrm{T} 7$ promoter, were named PC-Sc4CLVvSTS(P), PC-Os4CL-VvSTS(P), and PC-Le4CLVvSTS(P) (Table 1). Two STS genes from Arachis hypogea (AhSTS) and Picea abies (PaSTS) were cloned into EcoRV and $\mathrm{XhoI}$ of $\mathrm{PC}-\mathrm{O} 4 \mathrm{CL}$, respectively, and named PC-Os4CL-AhSTS(P) and PC-Os4CL-PaSTS(P), which are controlled by an independent T7 promoter (Table 1). In the case of AhSTS, since it has a HindIII restriction enzyme site at the 855 position, a silencing mutation was performed using PCR. To generate a construct in which two genes were controlled by one promoter, AhSTS, $V \nu S T S$, and PaSTS were amplified using each primer set containing EcoRI and HindIII sites and cloned into the corresponding sites of the pCDFDuet vector. Os4CL was amplified with a forward primer including a ribosomal binding site (RBS) and a NotI site such as 5-ATAAG CTTaggaggattacaaaATGATCACGGTGGCG-3 (the underlined part indicates the HindIII site and the RBS is shown in lower case), and the reverse primer including a NotI site such as 5-ATGCGGCCGCTTAGCT GCTTTTGGGCGCATC-3 (the underlined part indicates the NotI site) (Table 1). The resulting PCR product was digested with HindIII I and NotI of the restriction enzyme after gel purification and the corresponding sites of PCDFDuet vector containing AhSTS, VvSTS, or PaSTS. The resulting constructs, PC-AhSTS-Os4CL(O), 
Table 1 Plasmids, bacterial strains, and primers used in this study

\begin{tabular}{|c|c|c|}
\hline Plasmids/Strains & Description & Sources or reference \\
\hline \multicolumn{3}{|l|}{ Plasmids } \\
\hline pACYCDuet & P15A ori, $\mathrm{Cm}^{r}$ & Novagen \\
\hline pCDFDuet & CloDE13 ori, Str ${ }^{r}$ & Novagen \\
\hline PA-SeTAL & pACYCDuet carrying TAL from Saccharothrix espanaensis & \\
\hline PC-PC4CL-VvSTS(P) & $\begin{array}{l}\text { pCDFDuet carrying PC4CL from Petroselinum crispum and VVSTS from Vitis vinifera. The } \\
\text { genes are regulated by the respective T7 promoter }\end{array}$ & This study \\
\hline PC-SC4CL-VvSTS(P) & $\begin{array}{l}\text { PCDFDuet carrying Sc4CL from Streptomyces coelicolar A(3) and VvSTS from Vitis vinifera. } \\
\text { The genes are regulated by the respective T7 promoter }\end{array}$ & This study \\
\hline PC-Os4CL-VVSTS(P) & $\begin{array}{l}\text { pCDFDuet carrying Os4CL from Oryza sativa and VVSTS from Vitis vinifera. The genes are } \\
\text { regulated by the respective T7 promoter }\end{array}$ & This study \\
\hline PC-At4CL-VvSTS(P) & $\begin{array}{l}\text { pCDFDuet carrying At } 4 C L \text { from Arabidopsis thaliana and VVSTS from Vitis vinifera. The } \\
\text { genes are regulated by the respective T7 promoter }\end{array}$ & This study \\
\hline PC-Le4CL-VvSTS(P) & $\begin{array}{l}\text { pCDFDuet carrying Le } 4 C L \text { from Lithospermum erythrorhizon and VvSTS from Vitis vinifera. } \\
\text { The genes are regulated by the respective T7 promoter }\end{array}$ & This study \\
\hline PC-Os4CL-AhSTS(P) & $\begin{array}{l}\text { PCDFDuet carrying Os } 4 C L \text { from Oryza sativa and AhSTS from Arachis hypogaea. The genes } \\
\text { are regulated by the respective T7 promoter }\end{array}$ & This study \\
\hline PC-Os4CL-PaSTS(P) & $\begin{array}{l}\text { PCDFDuet carrying Os } 4 C L \text { from Oryza sativa and PaSTS from Picea abies. The genes are } \\
\text { regulated by the respective T7 promoter }\end{array}$ & This study \\
\hline PC-AhSTS-Os4CL(O) & $\begin{array}{l}\text { pCDFDuet carrying Os4CL from Oryza sativa and AhSTS from Arachis hypogaea. The genes } \\
\text { are regulated by one } T 7 \text { promoter }\end{array}$ & This study \\
\hline PC-PaSTS-Os4CL(O) & $\begin{array}{l}\text { pCDFDuet carrying Os4CL from Oryza sativa and PaSTS from Picea abies. The genes are } \\
\text { regulated by one T7 promoter }\end{array}$ & This study \\
\hline PC-VvSTS-Os4CL(O) & $\begin{array}{l}\text { pCDFDuet carrying Os4CL from Oryza sativa and VVSTS from Vitis vinifera. The genes are } \\
\text { regulated by one T7 promoter }\end{array}$ & This study \\
\hline PA-aroG-SeTAL-tyrA & pACYCDuet carrying TAL from S. espanaensis, aroG, and tyrA from E. coli & Kim el al. [18] \\
\hline PA-aroG ${ }^{\mathrm{fbr}}$-ppsA-tktA-SeTAL-tyrA ${ }^{\mathrm{fbr}}$ & pACYCDuet carrying TAL from S. espanaensis, aroG fbr , ppsA, tktA, and tyrA ${ }^{\text {fbr }}$ from E. coli & Kim el al. [18] \\
\hline \multicolumn{3}{|l|}{ Strains } \\
\hline BL21(DE3) & $\mathrm{F}^{-}$ompThsdS ${ }_{B}\left(\mathrm{r}_{\mathrm{B}}{ }^{-} \mathrm{m}_{\mathrm{B}}{ }^{-}\right)$gal dcm lon (DE3) & \\
\hline B-TP & BL21(DE3) $\triangle t y r R:: F R T-\Delta p h e A:: F R T-k a n^{R}-F R T$ & Kim et al. [18] \\
\hline B-TPFI & BL21(DE3) $\triangle t y r R:: F R T-\triangle p h e A .: F R T-\triangle f u m C: .: F R T-\triangle i c d A .: F R T-k a n^{R}$-FRT & This study \\
\hline BP-PC4CL & BL21(DE3) harboring PC-PC4CL-VVSTS(P) & This study \\
\hline $\mathrm{BP}-\mathrm{Os} 4 \mathrm{CL}$ & BL21(DE3) harboring PC-Os4CL-VvSTS(P) & This study \\
\hline BP-At4CL & BL21(DE3) harboring PC-At4CL-VvSTS(P) & This study \\
\hline BP-Sa4CL & BL21(DE3) harboring PC-Sa4CL-VvSTS(P) & This study \\
\hline BP-Le4CL & BL21(DE3) harboring PC-Le4CL-VvSTS(P) & This study \\
\hline BP-AhSTS & BL21(DE3) harboring PC-Os4CL-AhSTS(P) & This study \\
\hline BP-PaSTS & BL21(DE3) harboring PC-Os4CL-PaSTS(P) & This study \\
\hline BO-VvSTS & BL21(DE3) harboring PC-Os4CL-VvSTS(O) & This study \\
\hline BO-AhSTS & BL21(DE3) harboring PC-Os4CL-AhSTS(O) & This study \\
\hline BO-PaSTS & BL21(DE3) harboring PC-Os4CL-PaSTS(O) & This study \\
\hline BL101 & BL21(DE3) harboring PA-SeTAL and PC-VvSTS-Os4CL(O) & This study \\
\hline BL102 & BL21(DE3) harboring PA-aroG-SeTAL-tyrA and PC-VvSTS-Os4CL(O) & This study \\
\hline BL103 & BL21(DE3) harboring PA-aroG fbr-ppsA-tktA-SeTAL-tyr ${ }^{\text {fbr }}$ and PC-VvSTS-Os4CL(O) & This study \\
\hline BTP-S & BTP harboring PA-aroG fbr-ppsA-tktA-SeTAL-tyr A ${ }^{\text {fbr }}$ and PC-VvSTS-Os4CL(O) & This study \\
\hline BTPFI-S & BTPFI harboring PA-aroG Gbr-ppsA-tktA-SeTAL-tyrA ${ }^{\text {fbr }}$ and PC-VvSTS-Os4CL(O) & This study \\
\hline \multicolumn{3}{|l|}{ Primers } \\
\hline tyrR-F-Del & $\begin{array}{l}\text { GTGTCATATCATCATATTAATTGTTCTTTTTTCAGGTGAAGGTTCCCATGaattaaccctcactaaa- } \\
\text { gggcg }\end{array}$ & \\
\hline tyrR-R-Del & $\begin{array}{l}\text { TTGCACCATCAGGCATATTCGCGCTTACTCTTCGTTCTTCTTCTGACTCAtaatacgactcac- } \\
\text { tatagggctc }\end{array}$ & \\
\hline pheA-F-Del & $\begin{array}{l}\text { CCTCCCAAATCGGGGGCCTTTTTTATTGATAACAAAAAGGCAACACTATGaattaaccctcactaaa- } \\
\text { gggcg }\end{array}$ & \\
\hline
\end{tabular}


Table 1 (continued)

\begin{tabular}{|c|c|c|}
\hline Plasmids/Strains & Description & Sources or reference \\
\hline pheA-F-Del & $\begin{array}{l}\text { CACATCATCCGGCACCTTTTCATCAGGTTGGATCAACAGGCACTACGTTCtaatacgactcac- } \\
\text { tatagggctc }\end{array}$ & \\
\hline fumC-F-del & $\begin{array}{l}\text { TTAACGCCCGGCTTTCATACTGCCGACCATCTGTTCTGGCCGTACCCAGCaattaaccctcactaaa- } \\
\text { gggcg }\end{array}$ & \\
\hline fumC-R-del & $\begin{array}{l}\text { ATGAATACAGTACGCAGCGAAAAAGATTCGATGGGGGCGATTGATGTCCCtaatacgactcac- } \\
\text { tatagggctc }\end{array}$ & \\
\hline icdA-F-del & $\begin{array}{l}\text { ATGGAAAGTAAAGTAGTTGTTCCGGCACAAGGCAAGAAGATCACCCTGCAaattaaccctcactaaa- } \\
\text { gggcg }\end{array}$ & \\
\hline icdA-R-del & $\begin{array}{l}\text { TTACATGTTCTTGATGATCGCATCACCAAATTCTGAACATTTCAGCAGTTtaatacgactcac- } \\
\text { tatagggctc }\end{array}$ & \\
\hline Os4CL-BamHI & ATggatccGATGGGGTCGGTGGCGGCGG & \\
\hline Os4CL-Notl & ATgcggccgcTTAGCTGCTTTTGGGCGC & \\
\hline Os4CL2-HindllI-RBS & ATaagcttAGGAGGATTACAAAATGATCACGGTGGCG & \\
\hline Os4CL2-Notl & ATgcggecgcTCAGCACGCCGCGAGCTTGGCT & \\
\hline $\mathrm{Sc} 4 \mathrm{CL}-\mathrm{BamHI}$ & AAggatccGATGTTCCGCAGCGAGTACGCA & \\
\hline Sc4CL-Notl & AAgcggccgcTCATCGCGGCTCCCTGAGCT & \\
\hline Le4CL-BamHI & ATggatccGATGGACACTCAAACCAAAA & \\
\hline Le4CL-Notl & CAgcggccgcTAATTGTGTACACCATTTG & \\
\hline PC4CL-ECoRI & ATgaattcATGGGAGACTGTGTAGCACC & \\
\hline PC4CL-Notl & ATgcggccgcTTATTTGGGAAGATCACCGG & \\
\hline VvSTS-ECoRI & ATgaattcGATGGCTTCAGTCGAGGAATTT & \\
\hline VvSTS-Notl & ATgcggecgcTTAATTTGTAACCATAGGAA & \\
\hline VvSTS-HindIII & GCaagcttTTAATTTGTAACCATAGGAA & \\
\hline VvSTS-smal & ATcccgggGATGGCTTCAGTCGAGGAATTT & \\
\hline VvSTS-Xhol & ATctcgagTTAATTTGTAACCATAGGAATG & \\
\hline AhSTS-EcoRV & ATgatatcGATGGTGTCTGTGAGTGGAATT & \\
\hline AhSTS-Xhol & CAtctcgaGTTATATGGCCACACTGCGGAG & \\
\hline AhSTS-EcoRV & ATgatatcGATGGTGTCTGTGAGTGGAATT & \\
\hline AhSTS-Xhol & CATctcgagTTATATGGCCACACTGCGGAG & \\
\hline AhSTS-ECoRI & ATgaattcGATGGTGTCTGTGAGTGGAATCCGCA & \\
\hline AhSTS-HindIII & ATaagcttTTATATGGCCACACTGCGGAGA & \\
\hline AhSTS-Xbal & ATtctagaTTATATGGCCACACTGCGGAGAAC & \\
\hline AhSTS-HindIII silencing-F & TGACGCGCTCAATAAgGCTTTTGATCCATTG & \\
\hline AhSTS-Hindlll silencing- $R$ & CAATGGATCAAAAGCCTTATTGAGCGCGTCA & \\
\hline PsSTS-ECORV & ATgatatcGATGTCTGCAGGAATGACTGTT & \\
\hline PaSTS-Sall & ATgtcgacTCATGGAAGGAGAACGCTCTTA & \\
\hline PsSTS-EcoRI & ATgaattcGATGTCTGTAGGAATGGGCGTTGATTTGGAGGCTTTCAGGAA & \\
\hline PsSTS-HindIIII & ATaagcttTCATGGAAGGAGAACGCTCTTA & \\
\hline SeTAL-aflll & atcttaagTCATCCGAAATCCTTCCCGTC & \\
\hline T7-SeTAL-Notl & ATgcggccgcGGATCTCGACGCTCTCCCTTAT & \\
\hline aroG-EcoRl & ATgaattcgATGAATTATCAGAACGACGAT & \\
\hline aroG-Sall & ATgtcgacTTACCCGCGACGCGCTTTTACT & \\
\hline tyrA-Ndel & ATcatatgATGGTTGCTGAATTGACCGCAT & \\
\hline tyrA-Kpnl & CATggtaccTTACTGGCGGTTGTCATTCGC & \\
\hline ppsA-RBS-Xhol & ATctcgagAGGAGGCCATCCATGTCCAACAATGGCTCGTC & \\
\hline ppsA-Sall-Notl & ATgcggccgcGCTgtcgacTTATTTCTTCAGTTCAGCCAG & \\
\hline tktA-RBS-Xhol & ATctcgagAGGAGGCCATCCATGTCCTCACGTAAAGAGCT & \\
\hline tktA-Notl & CATgcggccgcTTACAGCAGTTCTTTTGCTTTC & \\
\hline
\end{tabular}


PC-VvSTS-Os4CL(O), and PC-PaSTS-Os4CL(O) contained a single promoter but an RBS site in front of each gene.

The aroG, tyrA, and feedback resistance mutants of $\operatorname{aroG}\left(\operatorname{aro} G^{\mathrm{fbr}}\right)$ and tyrA $\left(\mathrm{tyrA}^{\mathrm{fbr}}\right)$ were cloned in our previous study [18]. Briefly, to make the $\mathrm{pA}$-aro $G^{\mathrm{fbr}}$-ppsAtktA-SeTAL-tyrA ${ }^{\text {fbr }}$ construct, $\operatorname{aro}^{f b r}$ and $t y r A^{f b r}$ were introduced into the EcoRI and SalI sites and the Nde I and KpnI sites of pACYCDuet, respectively, and was named PA-aroG ${ }^{\mathrm{fbr}}$-tyrA ${ }^{\mathrm{fbr}}$. ppsA (phosphoenolpyruvate synthase) was amplified using PCR with the forward primer including an RBS and XhoI site, and a reverse primer containing SalI and NotI sites. The resulting PCR product was digested with the corresponding restriction enzymes and cloned into the SalI and NotI sites of PA-aro $G^{\mathrm{fbr}}$-tyrA ${ }^{\mathrm{fbr}}$ and named PA-aroG ${ }^{\mathrm{fbr}}$-ppsA-tyrA ${ }^{\mathrm{fbr}}$. $t k t A$ (Transketolase 1) was amplified using PCR with the forward primer containing an RBS and XhoI site and the reverse primer containing a NotI site. The resulting PCR product was digested with the corresponding restriction enzymes and cloned into the SalI and NotI sites of PA-aroG ${ }^{\mathrm{fbr}}$-tyrA ${ }^{\mathrm{fbr}}$ and named PA-aroG ${ }^{\mathrm{fbr}}$-ppsA-tktAtyrA ${ }^{\text {fbr }}$. SeTAL containing the T7 promoter and RBS was amplified with two primers expanded with the NotI and aflII sites using PA-SeTAL as a template. The PCR product was digested with $N o t I$ and aflII restriction enzymes. The resulting DNA fragment was cloned into the corresponding site of PA-aroG ${ }^{\mathrm{fbr}}$-ppsA-tktA-tyr $\mathrm{A}^{\mathrm{fbr}}$ and named PA-aroG ${ }^{\text {fbr }}$-ppsA-tktA-SeTAL-tyrA ${ }^{\text {fbr }}$ (Table 1).

\section{Deletion of $\Delta t y r R, \Delta p h e A, \Delta i c d A$, and $\Delta f u m C$}

The Quick and Easy Conditional Knockout Kit (Gene Bridges, Heidelberg, Germany) was used to prepare E. coli BL21 (DE3) mutants of four genes, tyrR (DNAbinding transcriptional dual regulator), pheA (chrismate mutase/prephenate dehydratase), icdA (isocitrate dehydrogenase), and fumC (fumarase C). Briefly, the tyrR gene of E. coli BL21 (DE3) was deleted using tyrRFRT-PGK-gb2-neo-FRT-tyrR cassette generated through PCR using two primers containing the tyrR-specific sequence of $50 \mathrm{bp}$, with FRT-PGK-gb2-neo-FRT as a template (Table 1). Luria-Bertani (LB) agar plates supplemented with $50 \mu \mathrm{L} / \mathrm{mL}$ kanamycin were used for the selection of positive colonies. The positive clones of tyrR deletion were checked using colony PCR. The positive clone selected was named BL21 $\Delta$ tyrR. To make $\Delta t y r R$ and $\Delta p h e A$ double mutants, BL21 $\Delta$ tyrR was used. A 708-FLPe expression plasmid encoding FLPe recombinase was used to remove the kanamycin cassette in BL21 tyrR. Colony PCR was used to verify the positive clone. The BL21 2 tyrR strain, a kanamycin cassette-free, was used to remove pheA using pheA-FRT-PGK-gb2neo-FRT-pheA cassette generated through PCR. The double deletion mutant of $t y r R$ and $p h e A$ was designated as BL21 tyrR-pheA. The quadruple mutant, BL21 $\Delta t y r R$ pheA-fumC-icdA, was generated by repeating the same methods as described above.

\section{Production of resveratrol from glucose and glycerol in $E$. coli}

To compare the effects of different constructs on the production of resveratrol, each construct was transformed into E. coli BL21 (DE3). Each E. coli transformant was grown overnight in LB broth containing the appropriate antibiotics at a concentration of $50 \mu \mathrm{g} / \mathrm{mL}$. The overnight cultured cells were transferred into fresh LB medium containing appropriate antibiotics, and the cells were grown until the $\mathrm{OD}_{600}$ reached 1.0. The cells were collected through centrifugation and then washed briefly with the M9 medium. The cell concentration was controlled to an $\mathrm{OD}_{600}$ of 1.0 , with $2 \mathrm{~mL}$ of M9 medium supplemented with $1 \%$ glucose or $1 \%$ glycerol, $1 \%$ yeast extract, and $1 \mathrm{mM}$ IPTG (Isopropyl $\beta$-D1-thiogalactopyranoside). The resulting culture was incubated at $30{ }^{\circ} \mathrm{C}$ for $48 \mathrm{~h}$ with shaking at $200 \mathrm{rpm}$. Samples $(200 \mu \mathrm{L})$ were collected and mixed with $1 \mathrm{~mL}$ of ethyl acetate. After vortexing and centrifugation, the upper ethyl acetate layer was transferred into a new $1.5 \mathrm{~mL}$ Eppendorf tube. The organic layer was evaporated to dryness, and the remaining residues were dissolved in $100 \mu \mathrm{L}$ of dimethyl sulfoxide (DMSO). The samples were analyzed using a Varian HPLC (High performance liquid chromatography) system equipped with a photodiode array detector and an Agilent Polaris 5 C18-A column $(250 \times 4.6 \mathrm{~mm})$ was used for the analysis of the reaction products using $20 \mu \mathrm{L}$ injection. The mobile phases consisted of $0.1 \%$ formic acid in water or acetonitrile. The program was $20 \%$ acetonitrile at $0 \mathrm{~min}, 45 \%$ acetonitrile at $10 \mathrm{~min}, 80 \%$ acetonitrile at $20 \mathrm{~min}, 90 \%$ acetonitrile at $20.1 \mathrm{~min}, 90 \%$ acetonitrile at $25 \mathrm{~min}, 20 \%$ acetonitrile at $25.1 \mathrm{~min}$, and $20 \%$ acetonitrile at $30 \mathrm{~min}$. The flow rate was $1 \mathrm{~mL} / \mathrm{min}$, and UV detection for the reaction products was dually monitored at 270 and $310 \mathrm{~nm}$.

\section{Results and discussion}

Production of resveratrol in $E$. coli from $p$-coumaric acid

To synthesize resveratrol from glucose in E. coli, at least three genes, namely $T A L, 4 C L$, and STS are necessary (Fig. 1). The TAL gene is mainly found in microorganisms, and the TAL gene of Saccharothrix espanaensis, which has been widely used in previous studies, was used in this study $[18,36]$. Two genes, $4 C L$ and STS, are more important for resveratrol production. Therefore, we decided to find the best combination of $4 C L$ and STS for resveratrol production from $p$-coumaric acid in $E$. coli BL21 (DE3). The 4CL gene is found simultaneously 
in microorganisms and plants. To select most effective genes for resveratrol biosynthesis, we tested four $4 C L$ genes, Pc4CL, Os4CL, and Le4CL from plants and Sc4CL from micororganism, through combination with $V v S T S$ for resveratrol production (Fig. 2). Four different combinations of $4 C L s$ and $V v S T S$, which are regulated by independent $\mathrm{T} 7$ promoter, were tested for resveratrol production from $p$-coumaric acid (Fig. 2a). BP-Os4CL harboring Os4CL and VvSTS showed the highest productivity of $16.2 \mathrm{mg} / \mathrm{L}$ after $12 \mathrm{~h}$ of incubation, followed by BP-Pc4CL containing Pc4CL and $V v S T S(8.1 \mathrm{mg} / \mathrm{L})$. However, Strains containing $S c 4 C L$ and $V v S T$ (BP-Sc4CL) or Le4CL and VvSTS (BP-Le4CL) produced resveratrol of less than $4 \mathrm{mg} / \mathrm{L}$. Based on the above results, we decided to use $O s 4 C L$ in subsequent experiments. Next, we tested six different combinations of three STSs (VvSTS, AhSTS, and PaSTS) and Os4CL, which were constructed either pseudo-operon or operon regulated by the $\mathrm{T} 7$ promoter for resveratrol production from $p$-coumaric acid in E. coli (Fig. 2b). E. coli harboring Os4CL and VvSTS pseudo-operon (BP-VvSTS) regulated by each T7 promoter or Os4CL and VvSTS operon (BO-VvSTS) regulated by one T7 promoter, showed the highest productivity at 15.1 and $19.8 \mathrm{mg} / \mathrm{L}$ after $24 \mathrm{~h}$ of incubation, respectively. Interestingly, BO-AhSTS strain containing the AhSTS and Os4CL operon produced only small amounts of resveratrol, whereas BP-AhSTS strain containing the AhSTS and Os4CL pseudo-operon produced $13.8 \mathrm{mg} / \mathrm{L}$ of resveratrol. E. coli containing either PaSTS and Os4CL pseudo-operon (BP-PaSTS) or PaSTS and Os4CL operon (BO-PaSTS) produced only small amounts of resveratrol (less than $4 \mathrm{mg} / \mathrm{L}$ ). These results indicate that the optimum combination of $S T S$ and $4 C L$ for balanced gene expression is critical for the production of resveratrol. We chose the VvSTS-Os4CL $(\mathrm{O})$ operon (E. coli strain BO-VvSTS) for further experiments.

\section{Production of resveratrol from glucose in E. coli}

Resveratrol biosynthesis in plants begins with cinnamic acid catalyzed by PAL with phenylalanine as the substrate (Fig. 1). Cinnamic acid is catalyzed by $\mathrm{C} 4 \mathrm{H}$ to form $p$-coumaric acid [34]. Since $\mathrm{C} 4 \mathrm{H}$ is a member of the $\mathrm{P} 450$ family, it is difficult to express it functionally in $E$. coli. For this reason, many studies related to the biosynthesis of phenolic compounds have used TAL, which converts tyrosine to $p$-coumaric acid $[18,35]$. In previous studies, $T A L$ cloned from $S$. espanaensis was used to biosynthesize various phenolic compounds in $E$. coli based on its excellent enzyme activity $[18,36]$. pA-SeTAL was transformed into the E. coli BL 100 strain, and the resulting strain, BL 101, was examined for the production of resveratrol from glucose. After a $24 \mathrm{~h}$ incubation, HPLC analysis of the reaction products showed two new peaks at 8.82 and $10.29 \mathrm{~min}$. Based on the HPLC retention
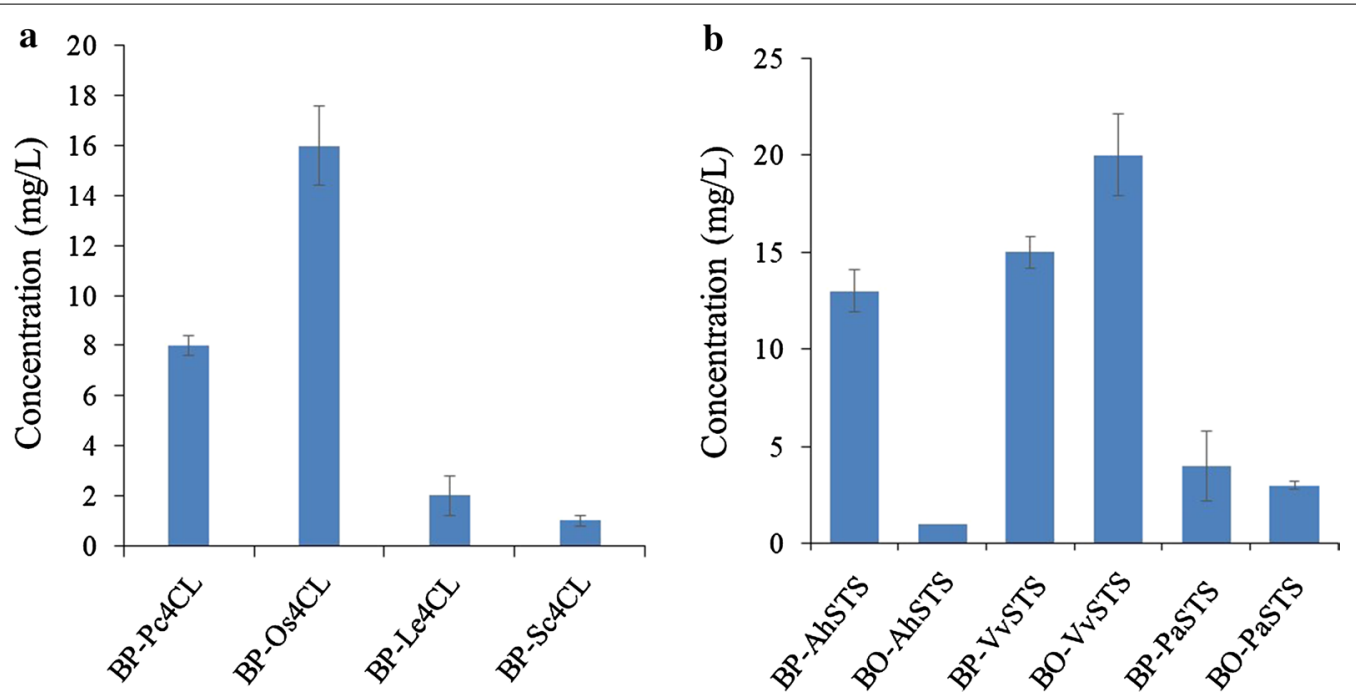

Fig. 2 Effect of different $4 \mathrm{CL}$ genes $(\mathbf{a})$ and STS genes (b) on the production of resveratrol. After $12 \mathrm{~h}$ of induction at $25^{\circ} \mathrm{C}$, the cells were collected through centrifugation and resuspended in $2 \mathrm{~mL}$ of $\mathrm{M} 9$ containing $1 \%$ yeast extract and $2 \%$ glucose. The cell density was adjusted to $\mathrm{OD}_{600}=3.0$. $\mathrm{p}$-Coumaric acid $(200 \mu \mathrm{M})$ was added and the cells were cultured at $30^{\circ} \mathrm{C}$. The culture was stopped after $6 \mathrm{~h}$ by adding two volumes of ethyl acetate. The reaction products were analyzed using HPLC. The error bars indicate mean values \pm from three independent experiments. $\mathrm{BP}-\mathrm{PC} 4 \mathrm{CL}$, BL21(DE3) harboring PC-Pc4CL-VvSTS(P); BP-Os4CL, BL21(DE3) harboring PC-Os4CL-VvSTS(P); BP-At4CL, BL21(DE3) harboring PC-At4CL-VvSTS(P); BP-Sa4CL, BL21(DE3) harboring PC-Sa4CL-VvSTS(P); BP-Le4CL, BL21(DE3) harboring PC-Le4CL-VvSTS(P); BP-AhSTS, BL21(DE3) harboring PC-Os4CL-AhSTS(P); BP-PaSTS, BL21(DE3) harboring PC-Os4CL-PaSTS(P); BO-VvSTS,BL21(DE3) harboring PC-Os4CL-VvSTS(O); BO-AhSTS,BL21(DE3) harboring PC-Os4CL-AhSTS(O); BO-PaSTSBL21(DE3) harboring PC-Os4CL-PaSTS(O) 
time, molecular mass, and UV absorbance, the two peaks at 8.82 and 10.29 min turned out to be $p$-coumaric acid and resveratrol, respectively (Fig. $3 \mathrm{a}-\mathrm{c}$ ). To further clarify the structure of P2, MS (Mass spectrometry) and NMR (Nuclear Magnetic Resonance) analyses were performed. In the negative ESI mode, P2 showed a molecular ion $[\mathrm{M}-\mathrm{H}]^{-}$at $m / z 227$, which was consistent with the molecular weight of resveratrol (Fig. 3d-f). For NMR analysis, one liter was cultured, the reaction product was extracted twice with the same amount of ethyl acetate, purified first using TLC, and then finally purified using HPLC and the same method as the analysis conditions. Finally, $5 \mathrm{mg}$ of the pure reaction product was obtained and used for ${ }^{1} \mathrm{H}$-NMR analysis. NMR was conducted as described by Kim et al. [37]. The structure of the reactants was determined by comparison with the structure published by Amalfitano et al. [38].

The NMR data was analyzed as follows: ${ }^{1} \mathrm{H}-\mathrm{NMR}$ $\left(400 \mathrm{MHz}\right.$, Acetone- $\left.d_{6}\right) ; \delta 7.41(2 \mathrm{H}, d, 8.58 \mathrm{~Hz}), \delta$ $7.01(1 \mathrm{H}, d, 16.3 \mathrm{~Hz}), \delta 6.88(1 \mathrm{H}, d, 16.3 \mathrm{~Hz}), \delta 6.83(2 \mathrm{H}, \mathrm{d}$, $8.6 \mathrm{~Hz}), \delta 6.5(2 \mathrm{H}, d, 2.11 \mathrm{~Hz})$, and $\delta 6.26(1 \mathrm{H}, t, 2.11 \mathrm{~Hz})$. The results were consistent with previously published results [38]. These results indicated that resveratrol was successfully synthesized from glucose in strain BL101 harboring SeTAL, VvSTS, and Os4CL, with a yield of
$13.8 \mathrm{mg} / \mathrm{L}$ (Fig. 4a). The production of BL101 (13.8 mg/L) was lower than that of $E$. coli strain BO-VvSTS $(19.8 \mathrm{mg} / \mathrm{L})$. This result is most likely due to insufficient supply of endogenous tyrosine in $E$. coli for resveratrol biosynthesis. Therefore, we decided to increase the supply of tyrosine, which is used as a precursor for $p$-coumaric acid biosynthesis.

\section{Engineering of $E$. coli to increase the production of resveratrol}

Although resveratrol was biosynthesized from glucose using the wild type E. coli strain containing three genes, the yield was not high. This was due to the limited supply of tyrosine. Therefore, we decided to increase the amino acid and tyrosine pool, which is the TAL substrate for $p$-coumaric acid biosynthesis, which was used as an entry point for resveratrol biosynthesis. To increase tyrosine levels, we overexpressed aroG and $\operatorname{tyr} A$, which encodes the rate-limiting enzymes in the shikimic acid biosynthetic pathway $[17,18]$. The aroG is converted into 3-deoxy-d-arabinoheptulosonate-7-phosphate using both phosphoenolpyruvate and erythrose 4-phosphate as substrates. tyrA is responsible for a two-step reaction from chorismate via prephenate to 4-hydroxy-phenylpyruvate. Additionally, two genes, aro $G^{f b r}$ and $t y r A^{f b r}$,

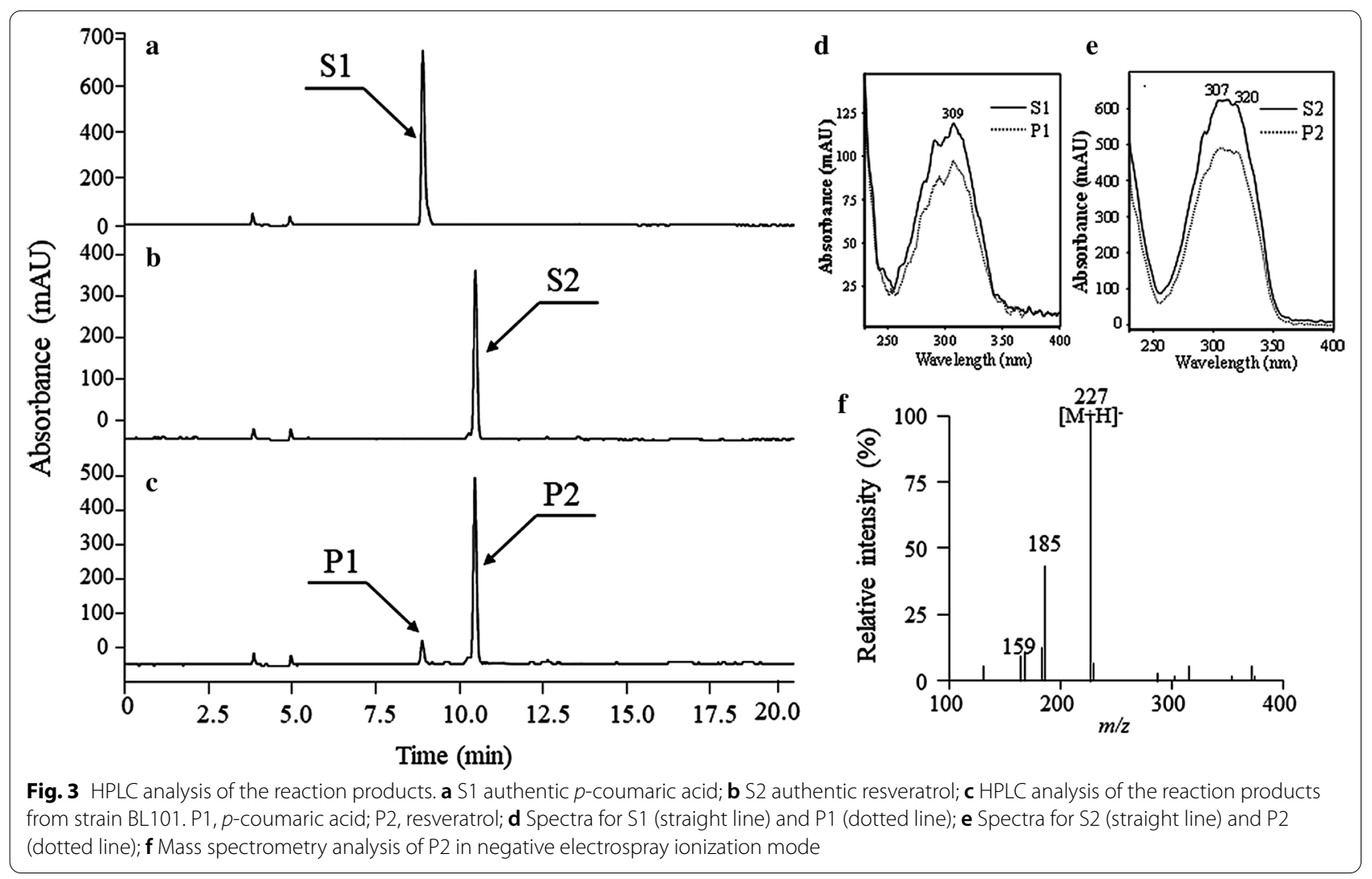



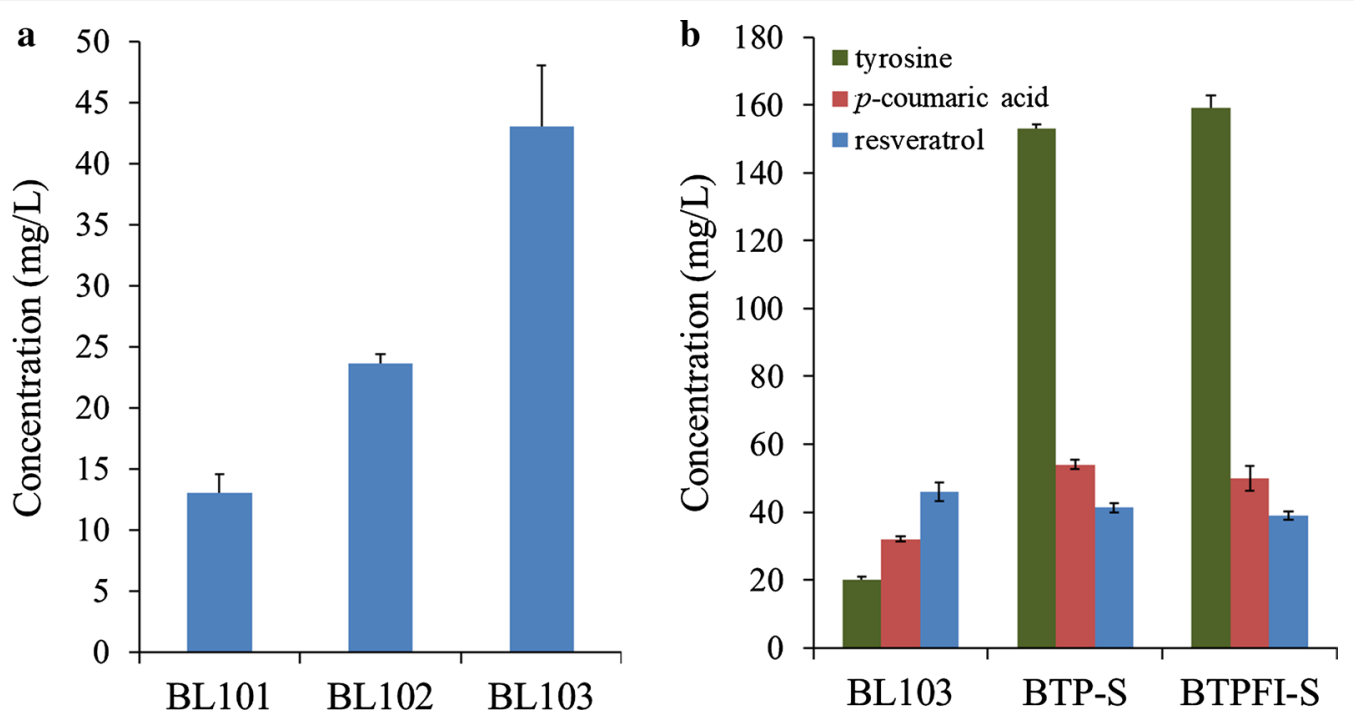

Fig. 4 Effect of different constructs for tyrosine production (a) and E. coli mutants (a) on the production of resveratrol. The concentration of the pre-cultured cells was adjusted to $\mathrm{OD}_{600}=1.0$, with $2 \mathrm{~mL}$ of $\mathrm{M} 9$ medium supplemented with $2 \%$ glucose, $1 \%$ yeast extract, and $1 \mathrm{mM}$ IPTG at the final concentration. The resulting culture was incubated at $30^{\circ} \mathrm{C}$ for $24 \mathrm{~h}$ with shaking at $200 \mathrm{rpm}$ and harvested after biotransformation for $24 \mathrm{~h}$. The reaction products were extracted with two volumes of ethyl acetate and analyzed via HPLC. The error bars indicate mean values \pm from three independent experiments. BL101,BL21(DE3) harboring PA-SeTAL and PC-VVSTS-Os4CL(O); BL102, BL21(DE3) harboring PA-aroG-SeTAL-tyrA and PC-VvSTS-Os4CL(O); BL103,BL21 (DE3) harboring PA-aroGfbr-ppsA-tktA-SeTAL-tyrAfbr and PC-VvSTS-Os4CL(O); BTP-S, BTP harboring PA-aroGfbr-pp sA-tktA-SeTAL-tyrAfbr and PC-VvSTS-Os4CL(O); BTPFI-S, BTPFI harboring PA-aroGfbr-ppsA-tktA-SeTAL-tyrAfbr and PC-VvSTS-Os4CL(O)

were overexpressed because aroG and tyrA are feedback inhibited by tyrosine. aroG ${ }^{\mathrm{fbr}}$, a mutant form of aroG, is not inhibited by the end product, tyrosine, unlike aroG (Fig. 1). In addition, tyrA was changed to tyr ${ }^{\mathrm{fbr}}$, which is not inhibited by the end product, tyrosine (Fig. 1) [17, 18]. Two genes, $p p s A$ and $t k t A$, which were overexpressed are involved in the biosynthesis of phosphoenolpyruvate and erythrose-4-phosphate, which are used as entrance compounds for the shikimic acid biosynthetic pathway. $E$. coli BL21(DE3) was used as the host strain for resveratrol production using three different vector sets, pA-SeTAL (BL101), pA-aroG-SeTAL (BL102), and pA-aroG ${ }^{\mathrm{fbr}}$-ppsAtktA-SeTAL-tyrA ${ }^{\text {fbr }}$ (BL103), along with the PC-VvSTSOs4CL operon. The resulting three E. coli strains were compared for resveratrol production. BL103 containing pA-aroG ${ }^{\mathrm{fbr}}$-ppsA-tktA-SeTAL-tyrA ${ }^{\mathrm{fbr}}$ produced a much greater amount $(42.9 \mathrm{mg} / \mathrm{L})$ of resveratrol, followed by strain BL102 (23.6 mg/L) (Fig. 4a). These results indicate that the increased supply of tyrosine in $E$. coli had a great effect on the biosynthesis of resveratrol. Thus, we decided to increase the tyrosine supply in $E$. coli by the deletion of two genes, $\operatorname{tyr} R$ and pheA, which have been reported to increase tyrosine levels in several studies. $\operatorname{tyr} R$ encodes a transcriptional regulatory protein for tyrosine biosynthesis. Its transcription is regulated by the feedback inhibition of the end product, tyrosine. In previous studies, the deletion of tyrR in $E$. coli increased tyrosine production
[18]. Because both tyrA and pheA compete to use prephenate as a substrate, $p h e A$ was deleted to induce tyrosine biosynthesis. Next, the removal of the $i c d A$ and fumC genes encoding isocitrate dehydrogenase and fumarate hydratase, respectively, has been reported to increase the amount of CoA in E. coli (Fig. 1) [18]. Therefore, the two genes were selected for engineering. This was expected to increase the biosynthesis of $p$-coumaroyl-CoA, which is used as an intermediate metabolite of resveratrol biosynthesis. As a result, three strains, BL21 DE3(wild type), B-TP (tyrA/pheA double mutant), and B-TPFI (tyrA/pheA/icdA/fumC quadruple mutant) were used to create three different strain sets along with two different vector sets, $\mathrm{pA}$-aroG ${ }^{\mathrm{fbr}}$-ppsA-tktA-SeTAL-tyrA ${ }^{\mathrm{fbr}}$ and PC-VvSTS-Os4CL operon. The three strains were named BL103, BTP-S, and BTPFI-S, and resveratrol production was compared for each strain. BTP-S and BTPFI-S produced $41.3 \mathrm{mg} / \mathrm{L}$ and $38.9 \mathrm{mg} / \mathrm{L}$, respectively, which was less than the yield of BL103 (50.3 mg/L) (Fig. 4b). In both the BTP-S and BTPFI-S strains, more than $150 \mathrm{mg} / \mathrm{L}$ of tyrosine was detected, whereas in the wild type, $21.7 \mathrm{mg} / \mathrm{L}$ of tyrosine was detected (Fig. 4b). In addition, BTP-S $(54.3 \mathrm{mg} / \mathrm{L})$ and BTPFI-S $(50.1 \mathrm{mg} / \mathrm{L})$ accumulated more $p$-coumaric acid than BL103 $(32.1 \mathrm{mg} / \mathrm{L})$. These results show that both tyrosine and $p$-coumaric acid increased in the mutant strains, but resveratrol did not. It seemed that the extra tyrosine or $p$-coumaric acid 
might inhibit the next two steps, $p$-coumaroyl-CoA synthesis or resveratrol synthesis. This resulted in a lower final yield of resveratrol in the mutant strains than in the wild type. Therefore, when resveratrol is synthesized from simple carbon sources, such as glucose and glycerol, balancing between the precursor and the product is critical for increasing the final yield. Recently, various methods, such as the co-culture methods, introduction of promoters of different strengths, and gene integration into the genome, have been attempted to resolve the metabolic imbalances. Among them, a co-culture method that divides the metabolic pathway necessary for the biosynthesis of phytochemicals into two or three strains has been frequently used as a method to overcome metabolic imbalance [35, 39]. To increase resveratrol biosynthesis, subsequent research such as a co-culture method should be conducted.

We explored the optimum culture method for resveratrol production using BL 103. First, we optimized the culture temperature. The cells were cultured at 25, 30, and $37{ }^{\circ} \mathrm{C}$. The production of resveratrol was the highest with $44.3 \mathrm{mg} / \mathrm{L}$ at $30{ }^{\circ} \mathrm{C}$, followed by $23.1 \mathrm{mg} / \mathrm{L}$ at $25{ }^{\circ} \mathrm{C}$ and $3.2 \mathrm{mg} / \mathrm{L}$ (Fig. 5a). Although the production of resveratrol was the lowest at $37{ }^{\circ} \mathrm{C}$, the production of
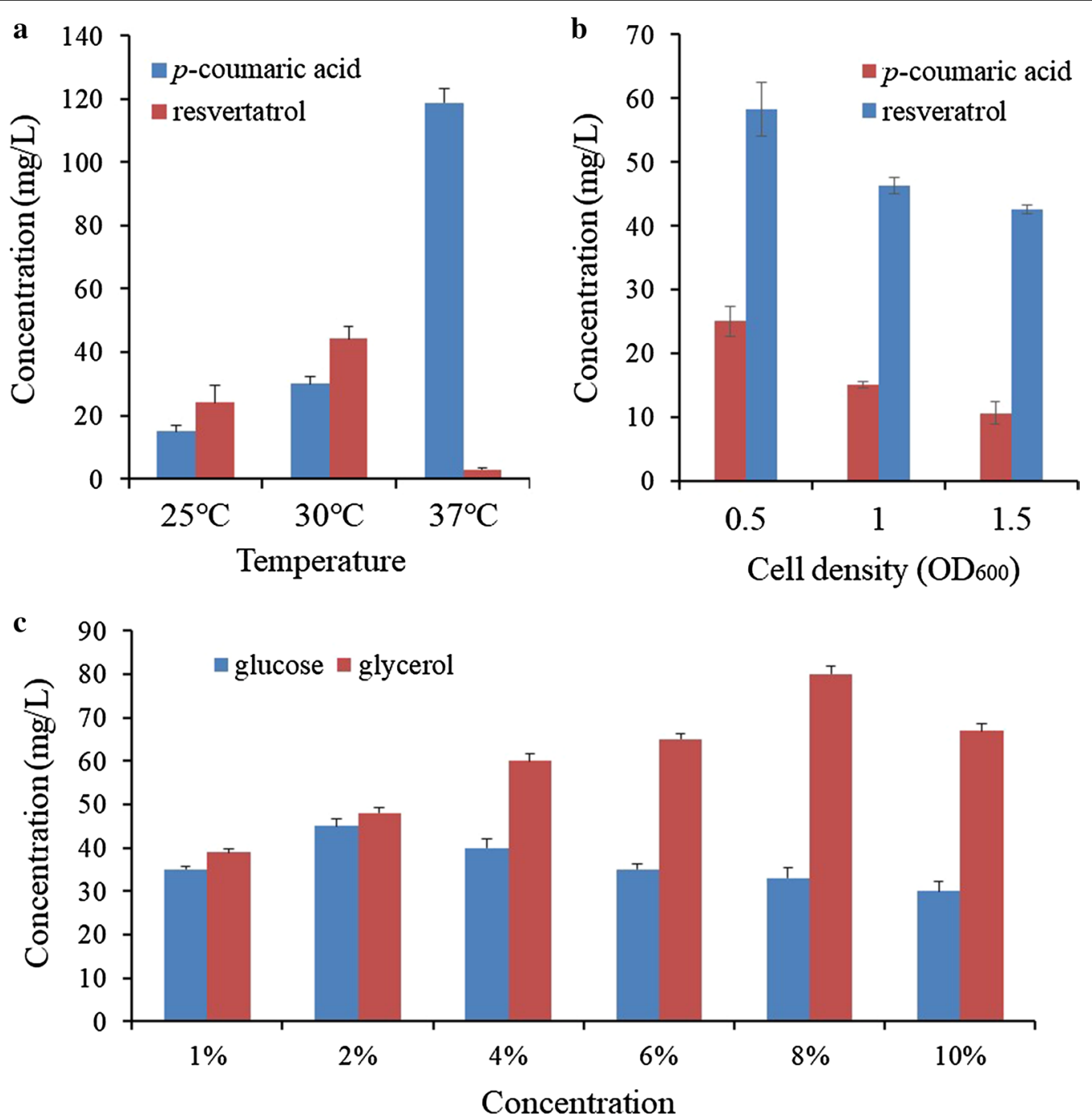

Fig. 5 Effect of biotransformation temperature (a), cell density (b), and different kinds and concentrations of carbon source (c) on the production of resveratrol. The concentration of the pre-cultured cells was adjusted to $\mathrm{OD}_{600}=1.0$, with $2 \mathrm{~mL}$ of $\mathrm{M} 9$ medium supplemented with $2 \%$ glucose, $1 \%$ yeast extract, and $1 \mathrm{mM} \mathrm{IPTG}$ at the final concentration for A and B. C was performed in the same manner as above, except for the carbon source. The resulting culture was incubated at $30^{\circ} \mathrm{C}$ for $24 \mathrm{~h}$ with shaking at $200 \mathrm{rpm}$ and harvested after biotransformation for $24 \mathrm{~h}$. The reaction products were extracted with two volumes of ethyl acetate and analyzed via HPLC. The error bars indicate mean values \pm from three independent experiments 
p-coumaric acid was the highest at $118.9 \mathrm{mg} / \mathrm{L}$ among the temperatures tested (Fig. 5a). These results suggest that the production of high amounts of proteins such as 4CL and STS may form inclusion bodies. The cells grown at $25{ }^{\circ} \mathrm{C}$ produced a lower amount of $p$-coumaric acid and resveratrol than those at $30{ }^{\circ} \mathrm{C}$. These results suggest that the cells cultivated at $25{ }^{\circ} \mathrm{C}$ did not produce enough proteins for resveratrol production owing to the low culture temperature. We also optimized cell culture density. The cell density was adjusted to $0.5,1,1.5$, and 2 at $\mathrm{OD}_{600}$. The optimal cell density was 0.5 at $\mathrm{OD}_{600}$, at which approximately $58.7 \mathrm{mg} / \mathrm{L}$ resveratrol was produced (Fig. 5b). However, as cell density increased, the production of resveratrol decreased. Next, we determined the optimal carbon sources and supply concentrations. The cell densities were adjusted to 0.5 at $\mathrm{OD}_{600}$ and glucose and glycerol were supplied at a rate of $1,2,4,6,8$, and $10 \%$. Overall, the productivity of resveratrol was higher when glycerol was used as a carbon source than glucose. When glycerol was used as a carbon source, the productivity of resveratrol increased as the supply concentration increased. The highest productivity of resveratrol was observed at a concentration of $8 \%$, at which approximately $78.9 \mathrm{mg} / \mathrm{L}$ of resveratrol was produced (Fig. 5c). In the case of glucose, the productivity was highest at a concentration of $2 \%$, at which approximately $45.4 \mathrm{mg} / \mathrm{L}$ of resveratrol was produced. However, as the concentration of glucose increased, the productivity of resveratrol gradually decreased.

Subsequently, resveratrol production from glycerol using the optimized conditions was monitored for $48 \mathrm{~h}$. $p$-Coumaric acid was observed after $8 \mathrm{~h}$ of incubation and it slightly increased with incubation time. The cell density gradually increased with incubation time. The highest density was observed after $24 \mathrm{~h}$ of incubation, at which time the cell density reached approximately 7.5 at $\mathrm{OD}_{600}$. After $24 \mathrm{~h}$ incubation, the cell density showed a tendency to gradually decrease. Resveratrol production was initiated after $8 \mathrm{~h}$ of incubation and it rapidly increased until $24 \mathrm{~h}$ of incubation. At this time, approximately $68.9 \mathrm{mg} / \mathrm{L}$ resveratrol was produced. After $24 \mathrm{~h}$ of incubation, resveratrol production slowly increased. After $40 \mathrm{~h}$ of incubation, resveratrol production was highest at $80.4 \mathrm{mg} / \mathrm{L}$ and then it slightly decreased (Fig. 6). Wang et al. [28] reported the biosynthesis of $114.4 \mathrm{mg} / \mathrm{L}$ of resveratrol from glucose, which was 1.4 times higher than that of this study. However, in the study of Wang et al. [28], resveratrol was biosynthesized by adding $3 \mathrm{mM}$ tyrosine to the culture medium, but we synthesized resveratrol from glucose without supplying tyrosine to the medium. For commercial application of resveratrol, a yield of at least $1.0 \mathrm{~g} / \mathrm{L}$ must be reached. However, the yield for this study

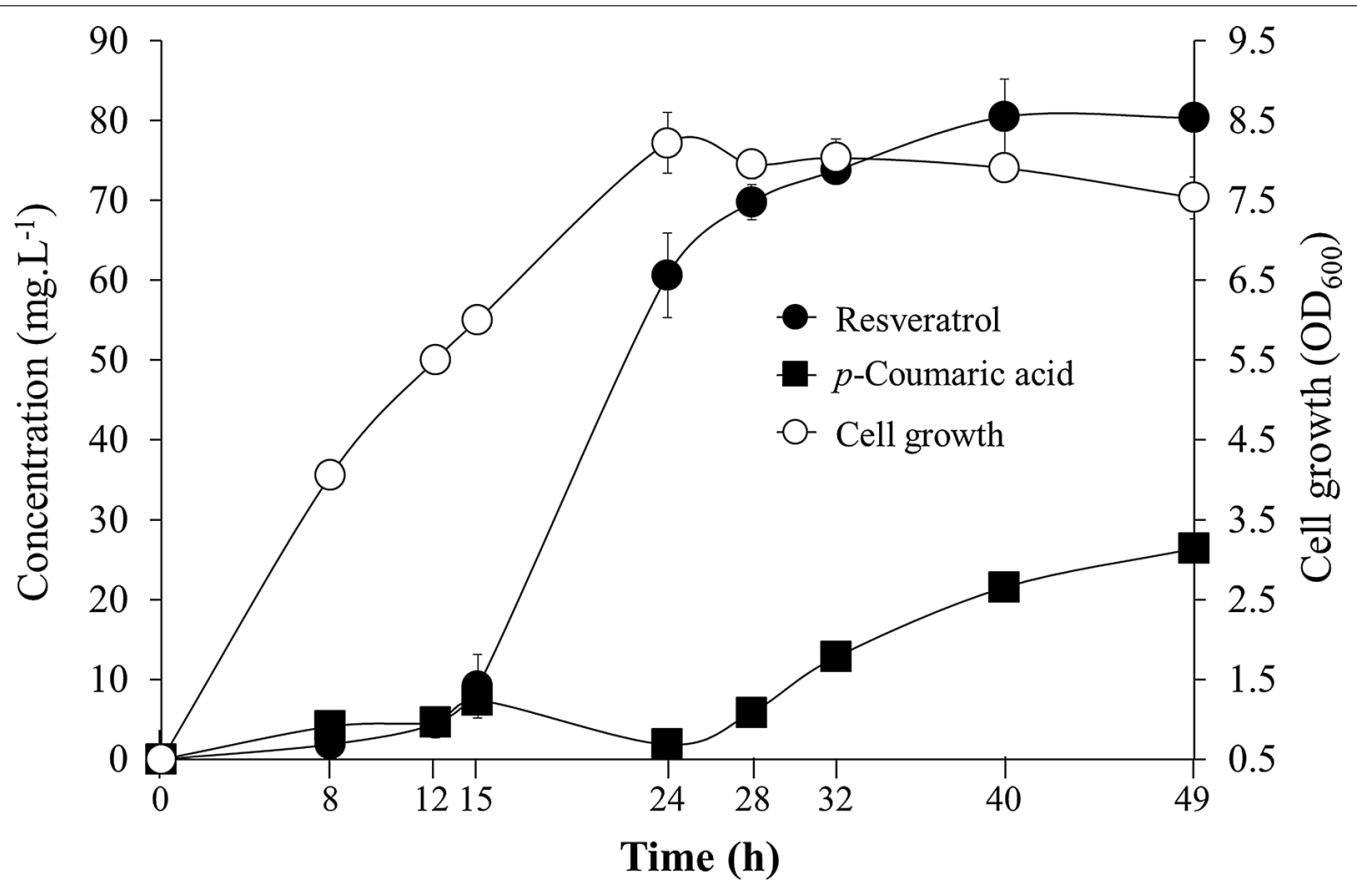

Fig. 6 Production of resveratrol by E. coli strain BL103. The concentration of the pre-cultured cells was adjusted to $\mathrm{OD}_{600}=0.5$, with $25 \mathrm{~mL}$ of $\mathrm{M} 9$ medium supplemented with $8 \%$ glycerol, $1 \%$ yeast extract, and $1 \mathrm{mM} \mathrm{IPTG}$ at the final concentration. The flask was incubated at $30^{\circ} \mathrm{C}$ for $49 \mathrm{~h}$ with shaking at $200 \mathrm{rpm}$, and the sample was periodically collected. The reaction products were extracted with two volumes of ethyl acetate and analyzed via HPLC. The error bars indicate mean values \pm from three independent experiments 
is $80.4 \mathrm{mg} / \mathrm{L}$. Of course, it is difficult to apply commercially with the current production amount, but if the culture conditions are optimized using a fermentor and the pathway for resveratrol biosynthesis is slightly improved, it will be possible to produce a sufficient amount required for commercial production.

\section{Conclusion}

Resveratrol is attracting much attention due to its various health benefits such as anticancer, antileukemic, and immune-modulating activities $[12,13]$. Since resveratrol is supplied by extraction from plants $[10,11]$, researchers recently attempted to biosynthesize resveratrol by introducing the resveratrol biosynthesis gene into microorganisms as an alternative production method for resveratrol [30-33]. There are several things to consider in order to biosynthesize resveratrol from a simple carbon source using microorganisms. First, resveratrol biosynthetic genes such as $4 C L$ and STS with high turnover rates should be selected. Second, a stable supply of tyrosine, the starting material for resveratrol biosynthesis, must be established. For the stable supply of tyrosine, the metabolic engineering of the tyrosine biosynthetic pathway of microorganisms must be achieved. Third, it is important to balance the metabolic pathways for resveratrol production without the metabolic load of intermediates such as tyrosine, $p$-coumaric acid and p-coumaroyl CoA. In this study, we attempted to produce resveratrol from simple carbon source, considering the problems presented above and optimized the culture system such as cell concentration, culture temperature, and carbon sources. Under optimized conditions, approximately $80.4 \mathrm{mg} / \mathrm{L}$ of resveratrol was produced after $48 \mathrm{~h}$ of culture using glycerol as a carbon source. Although we have successfully biosynthesized resveratrol from a simple carbon source, we need to further improve the biosynthesis of resveratrol in microorganisms. For this purpose, various methods, such as the co-culture methods, introduction of promoters of different strengths, and gene integration into the genome, must be attempted.

\footnotetext{
Abbreviations

PAL: Phenylalanine ammonia lyase; C4H: Cinnamic acid 4-hydroxylase; TAL: Tyrosine ammonia lyase; 4CL: 4-Coumarate-CoA ligase; STS: Stilbene synthase; HPLC: High-performance liquid chromatography; IPTG: Isopropyl- $\beta$-Dthiogalactoside; LB: Luria broth; ppsA: Phosphoenolpyruvate synthetase; tktA: Transketolase; tyrR: Phenylalanine DNA-binding transcription repressor; aroG: Deoxyphosphoheptonate aldolase; aroC: Chorismate synthase; tyrA: Prephenate dehydrogenase; pheA: Prephenate dehydratase; tyrB: Phenylalanine aminotransferase.
}

\section{Acknowledgements}

This study was supported by a grant from the Korea Forest Service's Forest Convergence Specialist Training Project (Support for Forest Industry Characterization Research, FTIS Assignment No. 2020186A00-2022-AA02) and by a grant from the Basic Science Research Program (NRF-2016R1D1A1B03933610).

\section{Authors' contributions}

BGK and JHA designed the experiments. JYP, JHL, and BGK performed the experiments and analyzed the data. JYP, JKL, JHA, and BGK wrote the manuscript. All authors read and approved the final manuscript.

\section{Funding}

Funding was received from the Korea Forest Service's Forest Convergence Specialist Training Project (Support for Forest Industry Characterization Research, FTIS Assignment No. 2020186A00-2022-AA02) and from the Basic Science Research Program (NRF-2016R1D1A1B03933610).

\section{Availability of data and materials}

All data generated or analyzed during the present study are included in this published article.

\section{Competing interests}

The authors declare that they have no competing interests.

\section{Author details}

${ }^{1}$ Department of Bioscience and Biotechnology, Bio/Molecular Informatics Center, Konkuk University, Seoul 143-701, Korea. ${ }^{2}$ Department of Forest Resources, Gyeongnam National University of Science and Technology, 33 Dongjin-ro, Jinju 52725, Gyeongsangman-do, Korea.

Received: 5 October 2020 Accepted: 25 January 2021

Published online: 05 February 2021

\section{References}

1. Abbas M, Saeed F, Anjum FM, Afzaal M, Tufail T, Bashir MS, Ishtiaq A, Hussain S, Suleria HAS (2017) Natural polyphenols: an overview. Int J Food Prop 20:1689-1699

2. Newman DJ, Cragg GM (2020) Natural products as sources of new drugs over the nearly four decades from 01/1981 to 09/2019. J Nat Prod 83:770-803

3. Del Bubba M, Di Serio C, Renai L, Scordo CVA, Checchini L, Ungar A, Tarantini F, Bartoletti R (2020) Vaccinium myrtillus L. extract and its native polyphenol-recombined mixture have anti-proliferative and pro-apoptotic effects on human prostate cancer cell lines. Phytother Res. https:// doi.org/10.1002/ptr.6879

4. Vogt T (2010) Phenylpropanoid biosynthesis. Mol Plant 3:2-20

5. Lattanzio V, Lattanzio V, Cardinali A, Imperato F (2006) Role of phenolics in the resistance mechanisms of plants against fungal pathogens and insects. In: Imperato F (ed) Phytochemistry: advances in research. Research Signpost, Trivandrum, Kerala, pp 23-67

6. Vattem DA, Ghaedian R, Shetty K (2005) Enhancing health benefits of berries through phenolic antioxidant enrichment: focus on cranberry. Asia Pac J Clin Nutr 14:120-130

7. Pezet R, Perret C, Jean-Denis JB, Tabacchi R, Gindro K, Viret O (2003) Deltaviniferin, a resveratrol dehydrodimer: one of the major stilbenes synthesized by stressed grapevine leaves. J Agric Food Chem 51:5488-5492

8. Borie B, Jeandet P, Parize A, Bessis R, Adrian M (2004) Resveratrol and stilbene synthase mRNA production in grapevine leaves treated with biotic and abiotic phytoalexin elicitors. Am J Enol Vitic 55:60-64

9. Jeandet P, Clément C, Cordelier S (2019) Regulation of resveratrol biosynthesis in grapevine: new approaches for disease resistance? J Exp Bot 70:375-378

10. Kimura Y, Kozawa M, Baba K, Hata K (1983) New constituents of roots of Polygonum cuspidatum. Planta Med 48:164-169

11. Das S, Das DK (2007) Resveratrol: a therapeutic promise for cardiovascular diseases. Recent Patents Cardiovasc Drug Discov 2:133-138

12. Baur JA, Sinclair DA (2006) Therapeutic potential of resveratrol: the in vivo evidence. Nat Rev Drug Discov 5:493-506

13. Singh AP, Singh R, Verma SS, Rai V, Kaschula CH, Maiti P, Gupta SC (2019) Health benefits of resveratrol: evidence from clinical studies. Med Res Rev 39:1851-1891

14. Giovinazzo G, Ingrosso I, Paradiso A, Gara LD, Santino A (2012) Resveratrol biosynthesis: plant metabolic engineering for nutritional improvement of food. Plant Foods for Hum Nutr 67:191-199 
15. Wang J, Yang Y, Yan Y (2018) Bioproduction of resveratrol. In: Schwab W, Lange B, Wüst M (eds) Biotechnology of natural products. Springer, Cham, pp 61-79

16. Braga A, Ferreira P, Oliveira J, Rocha I, Faria N (2018) Heterologous production of resveratrol in bacterial hosts: current status and perspectives. World J Microbiol Biotechnol 34:122

17. Juminaga D, Baidoo EEK, Redding-Johanson AM, Batth TS, Burd H, Mukhopadhyay A, Petzold CJ, Keasling J, JD, (2012) Modular engineering of L-tyrosine production in Escherichia coli. Appl Environ Microbiol 78:89-98

18. Kim MJ, Kim BG, Ahn JH (2013) Biosynthesis of bioactive O-methylated flavonoids in Escherichia coli. Appl Microbiol Biotechnol 97:7195-7204

19. Fraga CG, Croft KD, Kennedy DO, Tomás-Barberán FA (2019) The effects of polyphenols and other bioactives on human health. Food Funct 10:514-528

20. Durazzo A, Lucarini M, Souto EB, Carla C, Caiazzo E, Izzo AA, Novellino E, Santini A (2019) Polyphenols: A concise overview on the chemistry, occurrence, and human health. Phytother Res 33:2221-2243

21. Adams RP (1987) Yields and seasonal variation of phytochemicals from Juniperus species of the United States. Biomass 12:129-139

22. Trantas E, Panopoulos N, Ververidis F (2009) Metabolic engineering of the complete pathway leading to heterologous biosynthesis of various flavonoids and stilbenoids in Saccharomyces cerevisiae. Metab Eng 11:355-366

23. Chung IM, Rekha K, Rajakumar G, Thiruvengadam M (2018) Production of bioactive compounds and gene expression alterations in hairy root cultures of chinese cabbage elicited by copper oxide nanoparticles. Plant Cell, Tissue Organ Cult 134:95-106

24. Isah T, Umar S, Mujib A, Sharma MP, Rajasekharan PE, Zafar N, Frukh A (2018) Secondary metabolism of pharmaceuticals in the plant in vitro cultures: strategies, approaches, and limitations to achieving higher yield. Plant Cell, Tissue Organ Cult 132:239-265

25. Kim BG (2019) Optimization of bioactive isorhamnetin 3-O-glucoside production in Escherichia coli. J Appl Biol Chem 62:361-366

26. Yang D, Park SY, Park YS, Eun H, Lee SY (2020) Metabolic Engineering of Escherichia coli for Natural Product Biosynthesis. Trends Biotechnol 38:745-765

27. Yang SM, Shim GY, Kim BG, Ahn JH (2015) Biological synthesis of coumarins in Escherichia coli. Microb Cell Fact 14:65. https://doi.org/10.1186/ s12934-015-0248-y

28. Wang S, Zhang S, Xiao A, Rasmussen M, Skidmore C, Zhan J (2015) Metabolic engineering of Escherichia coli for the biosynthesis of various phenylpropanoid derivatives. Metab Eng 29:153-159
29. Bian G, Deng Z, Liu T (2017) Strategies for terpenoid overproduction and new terpenoid discovery. Curr Opin Biotechnol 48:234-241

30. Beekwilder J, Wolswinkel R, Jonker H, Hall R, de Vos CHR, Bovy A (2006) Production of resveratrol in recombinant microorganisms. Appl Environ Microbiol 72:5670-5672

31. Watts KT, Lee PC, Schmidt-Dannert C (2006) Biosynthesis of plant specific stilbene polyketides in metabolically engineered Escherichia coli. BMC Biotechnol 6:22

32. Lim CG, Fowler ZL, Hueller T, Schaffer S, Koffas MAG (2011) High-yield resveratrol production in engineered Escherichia coli. Appl Environ Microbiol 77:3451-3460

33. Yuan SF, Yi X, Johnston TG, Alper HS (2020) De novo resveratrol production through modular engineering of an Escherichia coli-Saccharomyces cerevisiae co-culture. Microb Cell Fact 19:143

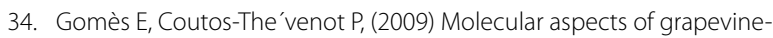
pathogenic fungi interactions. In: Roubelakis-Angelakis KA (ed) Grapevine molecular physiology \& biotechnology. Springer, Dordrecht, Netherlands, pp 407-428

35. Wang X, Shao A, Li Z, Policarpio L, Zhang H (2020) Constructing E. coli co-cultures for de novo biosynthesis of natural product acacetin. Biotech Method 15:2000131

36. Berner M, Krug D, Bihlmaier C, Vente A, Müller R, Bechthold A (2006) Genes and enzymes involved in caffeic acid biosynthesis in the actinomycete Saccharothrix espanaensis. J Bacteriol 188:2666-2673

37. Kim BG, Jung BR, Lee Y, Hur HG, Lim Y, Ahn JH (2006) Regiospecific flavonoid 7-O-methylation with Streptomyces avermitilis O-methyltransferase expressed in Escherichia coli. J Agric Food Chem 54:823-828

38. Amalfitano C, Evidente A, Surico G, Tegli S, Bertelli E, Mugnai L (2000) Phenols and stilbene polyphenols in the wood of esca-diseased grapevines. Phytopathol 39:178-183

39. Jones JA, Vernacchio VR, Collins SM, Shirke A, Xiu Y, Englaender JA, Cress B, McCutcheon CC, Linhardt R, Gross RA, Koffas MAG (2017) Complete biosynthesis of anthocyanins using E. coli polycultures. eBio 8:00621-17

\section{Publisher's Note}

Springer Nature remains neutral with regard to jurisdictional claims in published maps and institutional affiliations.

\section{Submit your manuscript to a SpringerOpen ${ }^{\odot}$ journal and benefit from:}

- Convenient online submission

- Rigorous peer review

- Open access: articles freely available online

- High visibility within the field

- Retaining the copyright to your article

Submit your next manuscript at $\boldsymbol{\nabla}$ springeropen.com 